\title{
GMR
}

\section{Cloning and transformation of INDUCER of CBF EXPRESSION1 (ICE1) in tomato}

\author{
X.H. Yu' ${ }^{1}$, J.X. Juan ${ }^{1}$, Z.L. Gao ${ }^{1}$, Y. Zhang ${ }^{2}$, W.Y. Li ${ }^{1}$ and X.M. Jiang ${ }^{1}$ \\ ${ }^{1}$ Key Laboratory of Biology and Genetic Improvement of Horticultural Crops, \\ Northeast Region, Ministry of Agriculture, Northeast Agriculture University, Harbin, \\ China \\ ${ }^{2}$ Heilongjiang Academy of Sciences Natural and Ecological Research Institute, \\ Xiangfang District, Harbin, Heilongjiang, China \\ Corresponding author: X.M. Jiang \\ E-mail: jxm0917@163.com \\ Genet. Mol. Res. 14 (4): 13131-13143 (2015) \\ Received April 26, 2015 \\ Accepted August 18, 2015 \\ Published October 26, 2015 \\ DOI http://dx.doi.org/10.4238/2015.October.26.9
}

ABSTRACT. The tomato plant (Solanum lycopersicum Mill.) is sensitive to cold, and low field temperatures can result in shortened growth periods and decreased crop yield. Transcription of CRT/DRE-binding factor (CBF) is regulated by INDUCER of CBF EXPRESSION1 (ICE1). CBF activates many downstream genes that confer cold tolerance on plants. ICE1 has been used in genetic engineering to improve cold-resistance in several plant species. Here, ICE1 in a plant expression vector was used to transform a tissue-cultured rhubarb tomato variety using Agrobacterium tumefaciens. The transgenic and control plants were compared at $4^{\circ} \mathrm{C}$ for 0,24 , and $72 \mathrm{~h}$. We measured leaf physiological indicators related to cold resistance, including malondialdehyde (MDA) and proline (Pro) contents, and peroxidase (POD) and catalase (CAT) activities. At $72 \mathrm{~h}$, the MDA content in transgenic plants was significantly lower than in control plants, indicating a lower membrane lipid injury. The Pro contents and the CAT and POD activities in the transgenic plants increased significantly compared with those of the control plants. For Pro, the increase continued over the prolonged stress exposure, while CAT and POD activities reached peak 
levels at $24 \mathrm{~h}$. These results are consistent with the roles of Pro, CAT, and POD in defending the integrity of plant cells. Our study not only improves the cold resistance of tomato, but also provides the foundation for further research on the role of ICE 1 as a transcription factor in plant cold resistance.

Key words: Transcription factor; ICE1 gene; Cold tolerance; Tomato

\section{INTRODUCTION}

The tomato plant (Lycopersicon esculentum Mill.) is a highly cold-sensitive crop. At temperatures of 10,8 , and $5^{\circ} \mathrm{C}$, its growth is respectively affected, incrementally decreased, and then stopped completely. Low temperatures often result in a shorter growth period, growth retardation, plant dwarfism, and decreased yield (Lin et al., 2000). In recent years, studies addressing cold tolerance found that cold-induced genes play important roles in the tomato plant's resistance to low temperatures and cold acclimation (Thomashow, 1999). The transcription factor CRT/DRE-binding factor (CBF) binds to the promoter of a low temperature-induced gene containing the CRT/DRE regulatory elements to regulate the gene's expression level when induced by a series of low temperatures, and to improve the plant's cold resistance (Stockinger et al., 1997; Liu et al., 1998). CBF has been widely used in genetic engineering to improve cold resistance in crops (Hsieh et al., 2002; Savitch et al., 2005). CBF can also regulate the expression levels of multiple functional genes in plants under drought, high salt, and low-temperature stresses. Li et al. (2010) found that CBF1 is expressed in cucumber plants under low temperature and salt stresses, but not under drought or abscisic acid stress.

The regulation of transcription factors and effector genes, collectively called coldregulated (COR) genes, is necessary for cold tolerance. INDUCER of CBF EXPRESSION1 (ICE1) is an upstream transcription factor that controls the transcription of $C B F$, which activates many downstream genes to confer cold tolerance on plants. ICE1 encodes a bHLH transcription factor similar to the transcriptional activation gene, $M Y C$, which is inactive at normal temperatures but specifically binds with $C B F 3$ promoter sequences at low temperatures, inducing CBF3 expression. When $C B F 3$ binds to the DRE sequence in the promoter of a downstream gene, it induces the expression of a series of downstream COR genes and other genes that play a role in the plant's adaptation to cold. Up-regulating this pathway, using an ICE1 transgene, has been shown to improve cold resistance and growth, without producing abnormalities (Chinnusamy et al., 2003). Presently, transgenic ICE1 plants, including Arabidopsis (Chinnusamy et al., 2003), citrus (Huang, 2005), Populus suaveolens (Lin et al., 2007), apple (Zhao, 2007), Cymbidium (Zhang et al., 2008), rice (Xiang et al., 2008), tobacco (Zheng et al., 2009; Lin et al., 2011), cucumber (Liu et al., 2010), and chrysanthemum (Chen et al., 2012), have improved cold resistance when compared with non-transgenic plants. In the present research, we transformed the tissue-cultured rhubarb tomato variety with ICE1 in a plant expression vector using Agrobacterium tumefaciens. These experiments were designed not only to significantly improve the cold resistance of the tomato plant, but also to provide information to assist further studies on the role of ICE1 in cold resistance.

\section{MATERIAL AND METHODS}

\section{Material}

The experiments were performed in the research center of the Northeast Agricultural 
University and Education Ministry's Key Laboratory of Biology for Vegetables in Cold Regions in Heilongjiang Province in 2007 to 2009.

\section{Tomato}

The tomato variety used was a tissue culture-derived rhubarb tomato, provided by Education Ministry's Key Laboratory of Biology for Vegetables in Cold Regions in Heilongjiang Province. The variety was grown in a tissue culture incubator to produce plant materials for transformation.

\section{Vector and reagent}

Recombinant plasmid pMD18-ICE1 was contributed by Associate Professor Yinying Zheng, College of Life Sciences, Shihezi University, and Agrobacterium strain EHA105 and plant expression vector pCAMBIA3301 (referred to as p3301 thereafter) were contributed by Associate Professor Wang Yong, Northeast Agricultural University. Restriction endonucleases (Ncol and BstEII), T4 DNA ligase, kanamycin (Kan), and carboxybenzyl penicillin (Carb) were purchased from the Takara Company (Takara, Japan). Molecular weight markers Trans2k and Trans15k were purchased from TransGen Biotech Co., Ltd. (Beijing, China).

\section{Culture media}

The media used in the experiments included basal medium containing Murashige and Skoog medium (MS) + $2.0 \mathrm{mg} \cdot \mathrm{L}^{-1}$ 6-benzyladenine $(6-\mathrm{BA})+0.2 \mathrm{mg} \cdot \mathrm{L}^{-1}$ indoleacetic acid (IAA); coculture medium containing $M S+2.0 \mathrm{mg} \cdot \mathrm{L}^{-1} 6-\mathrm{BA}+0.2 \mathrm{mg} \cdot \mathrm{L}^{-1} \mathrm{IAA}$; selective medium containing $\mathrm{MS}+2.0 \mathrm{mg} \cdot \mathrm{L}^{-1} 6-\mathrm{BA}+0.2 \mathrm{mg} \cdot \mathrm{L}^{-1} \mathrm{IAA}+20 \mathrm{mg} \cdot \mathrm{L}^{-1} \mathrm{Kan}+300 \mathrm{mg} \cdot \mathrm{L}^{-1} \mathrm{Carb}$; and rooting medium containing $1 / 2 \mathrm{MS}+0.5 \mathrm{mg} \cdot \mathrm{L}^{-1} \mathrm{IAA}+10 \mathrm{mg} \cdot \mathrm{L}^{-1} \mathrm{Kan}+300 \mathrm{mg} \cdot \mathrm{L}^{-1} \mathrm{Carb}$.

\section{Methods}

\section{Primer design and polymerase chain reaction (PCR)}

Primers were designed based on the $A$. thaliana ICE1 mRNA sequence (GenBank accession No. AY195621) as reported by Chinnusamy et al. (2003). The upstream primer P1 (5'-CCATGGGTCTTGACGGAAACAAT-3') and downstream primer P2 (5'-GGTAACCTCAGATCAT ACCAGCATACCCTG-3') were synthesized with Ncol and BstEll sites, respectively. PCR conditions were as follows: pre-denaturation at $94^{\circ} \mathrm{C}$ for $5 \mathrm{~min}$; denaturation at $94^{\circ} \mathrm{C}$ for $30 \mathrm{~s}$, following by 30 cycles of annealing at $59^{\circ} \mathrm{C}$ for $30 \mathrm{~s}$, extension at $72^{\circ} \mathrm{C}$ for $1 \mathrm{~min}$, and final extension at $72^{\circ} \mathrm{C}$ for $10 \mathrm{~min}$. The PCR reactions contained $1 \mu \mathrm{L}$ template, $2.5 \mu \mathrm{L} 10 \mathrm{X}$ Taq buffer, $2.5 \mu \mathrm{L} 2.5$ $\mathrm{mmol} \cdot \mathrm{L}^{-1} \mathrm{dNTP}, 1 \mu \mathrm{L}$ each primer, $0.1 \mu \mathrm{L}$ Taq DNA polymerase, and water to $25 \mu \mathrm{L}$. After agarose gel electrophoresis, PCR products were recovered using a DNA Gel Extraction Kit (Harbin Marine Biotechnology Co., Harbin, China).

\section{Construction of the expression vector p3301-ICE1}

ICE1 and p3301 were cut with Ncol and BstEll and purified for ligation with T4 DNA ligase. The ligation reactions were transformed into $E$. coli DH5a competent cells using the freeze and thaw 
method, and plated out and screened for positive colonies. Plasmid DNA was extracted and sequenced.

\section{Agrobacterium transformation}

Recombinant expression plasmids were transformed into Agrobacterium EHA105 by freezing and thawing in liquid nitrogen, and plated on YEB agar medium containing $50 \mathrm{mg} \cdot \mathrm{L}^{-1}$ Kan. Colonies were picked up after $48 \mathrm{~h}$, and individually grown in liquid medium on a shaker. The plasmid was extracted and used as a template for PCR amplification with the gene-specific primers $\mathrm{P} 1$ and $\mathrm{P} 2$. The transformed $A$. tumefaciens EHA105 was stored at $-80^{\circ} \mathrm{C}$ for subsequent use.

\section{Tomato transformation}

Under sterile conditions, the tomato cotyledons were cut into squares of $0.5 \mathrm{~cm} \times 0.5 \mathrm{~cm}$, and then placed on the pre-culture medium for two days. A. tumefaciens EHA105 containing the recombinant plasmid p3301-ICE1 was grown with shaking to an OD600 of between 0.4 and 0.6, and used for infecting the pre-cultured cotyledon tissue. The infection lasted 8 to $10 \mathrm{~min}$ and excess bacterial liquid was blot-dried. The infected explants were placed on the co-culture medium for 36 $\mathrm{h}$, and then on the selective medium, which was changed every $14 \mathrm{~d}$. When the cotyledon calli differentiated into small buds, the buds were cut off and placed on the rooting medium containing Kan to regenerate resistant seedlings.

\section{Detection of transgene and analysis of transgene expression}

The genomic DNA of regenerated tomatoes was used as template in PCR reactions to screen and identify positive plants. Non-transgenic rhubarb tomatoes were used as a negative control. For quantitative reverse transcriptase PCR (qRT-PCR), a housekeeping gene was used as an internal control. Using the Trizol method, total RNA from PCR positive-plants was extracted (after exposure to dark conditions in an incubator at $4^{\circ} \mathrm{C}$ for $12 \mathrm{~h}$ ) and qRT-PCR was performed. The transformed and control plants were grown at $4^{\circ} \mathrm{C}$ for 0,24 , and $72 \mathrm{~h}$, and harvested to measure the leaf physiological indicators related to cold resistance, such as malondialdehyde (MDA) and proline (Pro) contents, and peroxidase (POD) and catalase (CAT) activities. The experiments were conducted in triplicate and the data were averaged. The ninhydrin colorimetric method was used to measure Pro content (Zou, 1998), the thiobarbituric (TBA) method was used to measure the MDA content (Zhang et al., 1989), the guaiacol method was used to measure POD activity (Cakmak and Marschner, 1992), and the hydrogen peroxide decomposition volume method was used to measure CAT activity (Zhao et al., 1998).

\section{Data analysis}

Microsoft Excel software was used for the statistical analysis.

\section{RESULTS}

\section{PCR amplification of ICE1}

With the plasmid pMD18-ICE1 as the template, and P1 and P2 as the primers, the cDNA coding region of ICE1 was amplified, producing a band of anticipated size (1500 bp, Figure 1). 


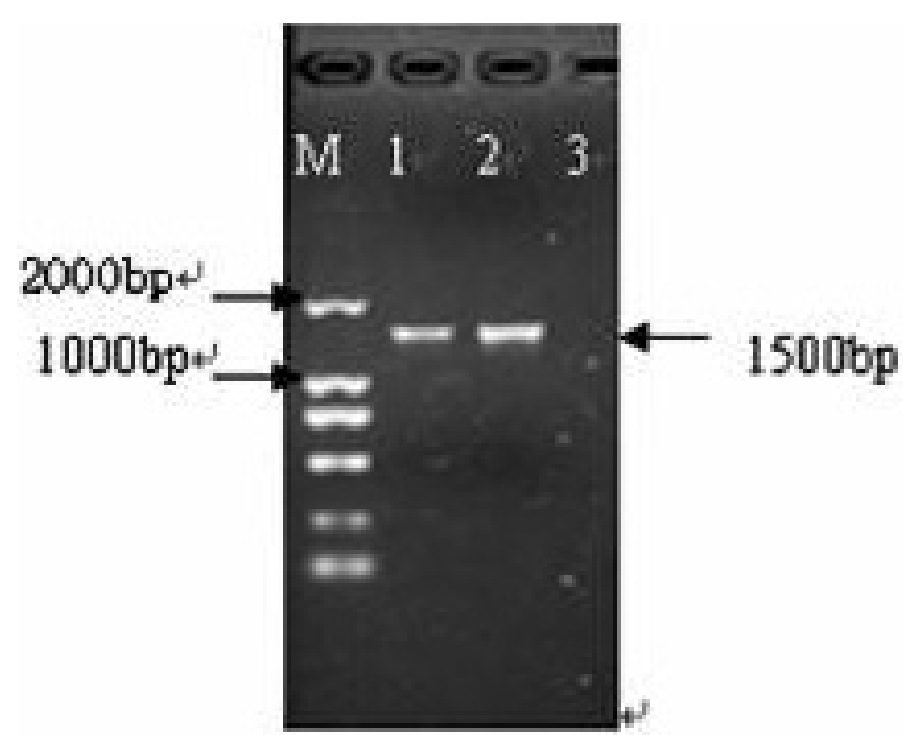

Figure 1. Electrophoresis of the PCR products of pMD18-ICE1. Lanes 1 and 2, pMD18-ICE1; Lane 3, water; M, DNA marker Trans2k.

\section{Construction of p3301-/CE1}

The recombinant plasmid p3301-ICE1 was verified by an Ncol and BstEll double digestion and produced expected PCR bands at $1500 \mathrm{bp}$ (Figure 2-1, 2-2). The Bg/ll (located at $169 \mathrm{bp}$ inside ICE1) digestion produced a band of approximately $169 \mathrm{bp}$ (Figure 2-3), indicating that the expression vector p3301-ICE1 obtained contained ICE1.

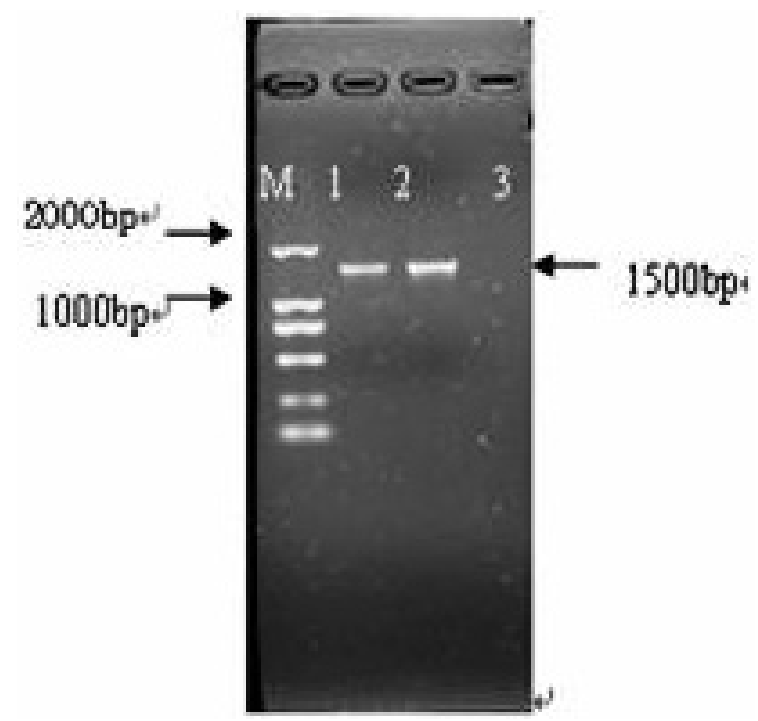

Figure 2-1. Electrophoresis of PCR products of p3301-ICE1. Lane 1, pMD18-ICE1 amplification products; Lane 2, p3301 amplification products; Lane 3, water; M, DNA marker Trans2k. 


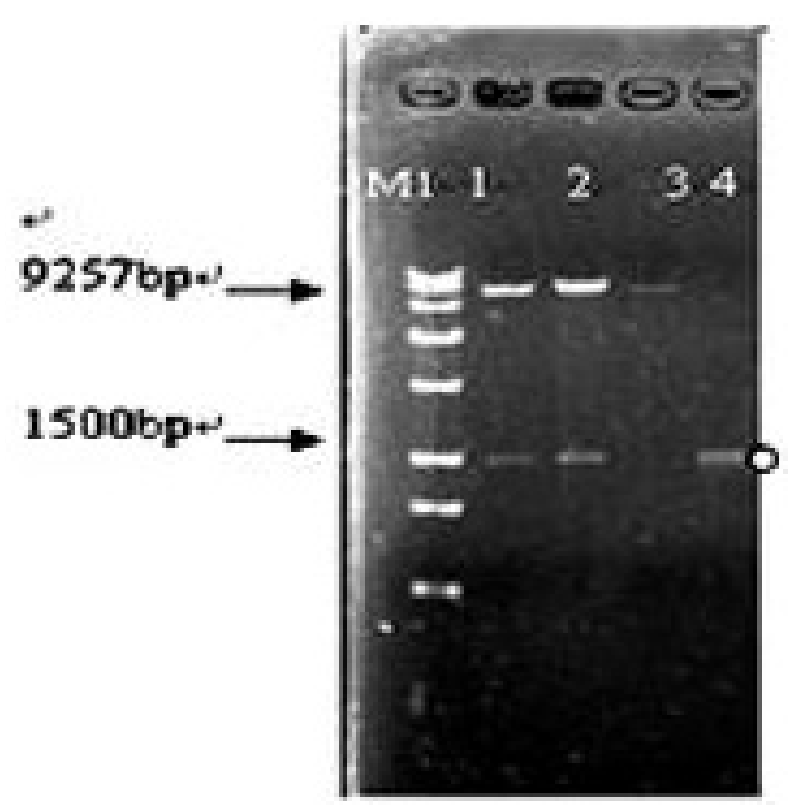

Figure 2-2. Enzyme-digested products of plant expression vector p3301-ICE1. Lanes 1 and 2, p3301-ICE1; Lane 3, P3301; Lane 4, pMD18-ICE1 amplification products; M, DNA marker Trans15k.

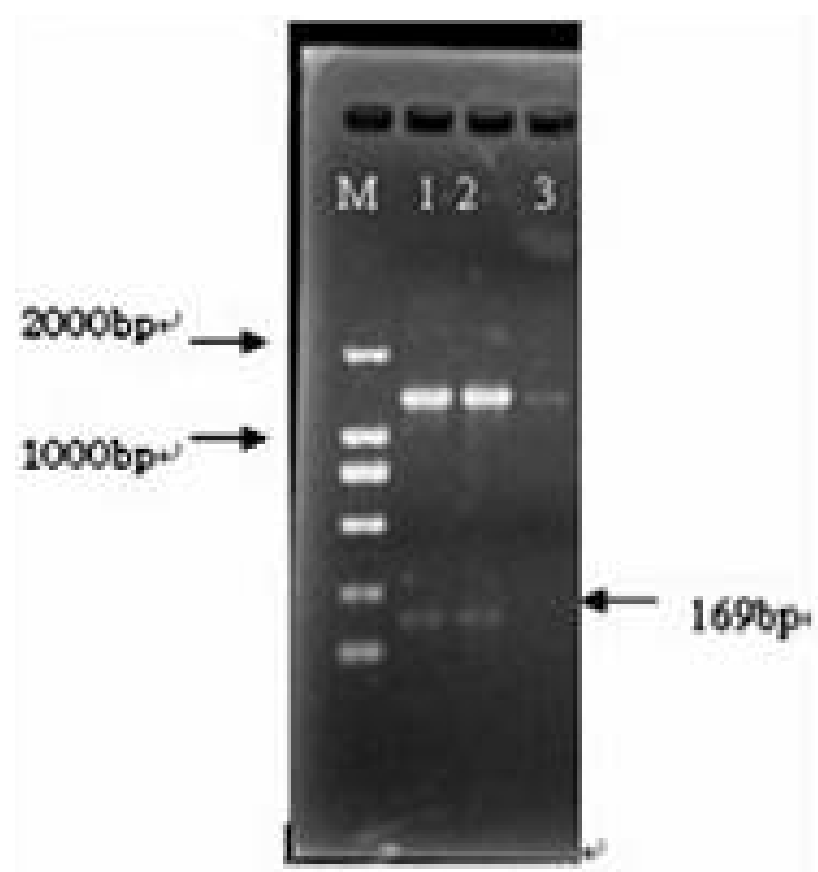

Figure 2-3. Bglll-digested electrophoresis pattern. Lane 1, pMD18-ICE1 digested by BgIII; Lane 2, p3301-ICE1 digested by Bglll; Lane 3, pMD18-ICE1 amplification products; M, DNA marker Trans2k. 


\section{Transformation of p3301-ICE1 into Agrobacterium EHA105}

When ICE1-specific primers P1 and P2 were used to amplify the DNA from Agrobacterium EHA105 transformation with p3301-ICE1, an amplicon of expected 1500 bp was obtained, indicating the strain was successful (Figure 3).

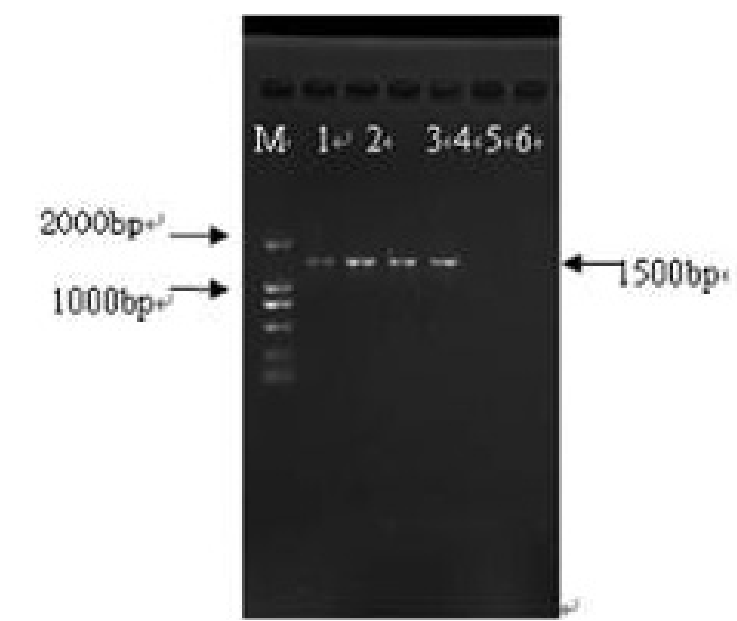

Figure 3. PCR product of Agrobacterium EHA105 in individual colonies transformed with p3301-ICE1. Lane 1, p3301-ICE1; Lanes 2-4, Agrobacterium EHA105 (p3301-ICE1) colonies; Lane 5, water; Lane 6, non-transformed Agrobacterium EHA105; M, DNA marker Trans2k.

\section{Transgenic production}

Transformed tomato cotyledons were placed on the selection medium and approximately 14 days later calli began to appear (Figure 4a), and they differentiated into bud clusters approximately 40 days later (Figure $4 \mathrm{~b}$ ). When the buds grew to approximately $2 \mathrm{~cm}$ long (Figure 4c), they were cut off and transferred to rooting medium. Approximately 10 days later, the tomato plants began to root (Figure 4d). Finally, five normally growing tomato plants transformed with ICE1 were produced.

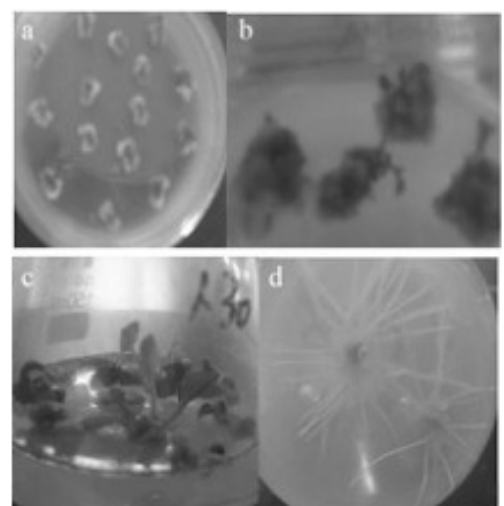

Figure 4. Transgenic tomato plants containing ICE1 after Agrobacterium tumefaciens-mediated transformation. a, calli; b, differentiation of callus and bud clusters; c, growth of bud clusters; $d$, rooting. 


\section{Molecular analysis of transgenic tomato}

The genomic DNA was extracted from Kan-resistant plants using the CTAB method (Figure 5-1) and used for a PCR analysis with the ICE1-specific primers P1 and P2. The results revealed expected bands (1500 bp) in three tomato plants and the positive control (Figure 5-2). These three PCR-positive plants were subjected to a $4^{\circ} \mathrm{C}$ low temperature treatment for $12 \mathrm{~h}$, and an RT-PCR analysis revealed that the three plants had intact ICE1 RNA (Figure 5-3) and the amplicons were 1500 bp long (Figure 5-4).

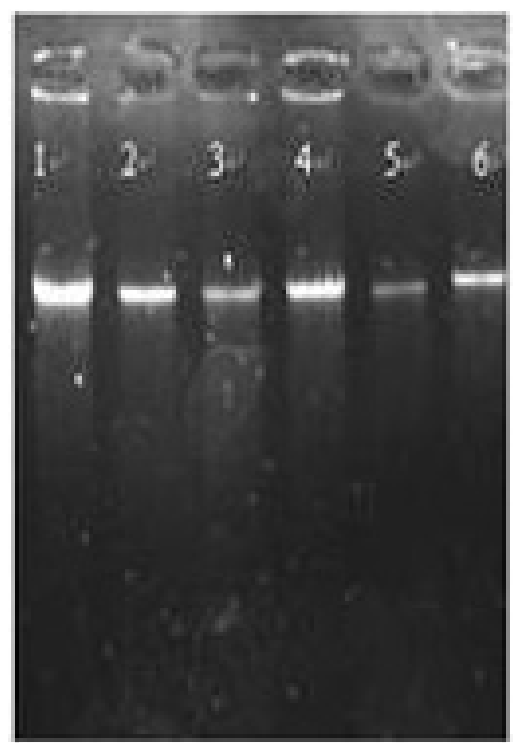

Figure 5-1. Electrophoresis of ICE1 transgenic tomato DNA. Lanes 1-5, transgenic tomato; Lane 6, non-transformed tomato.

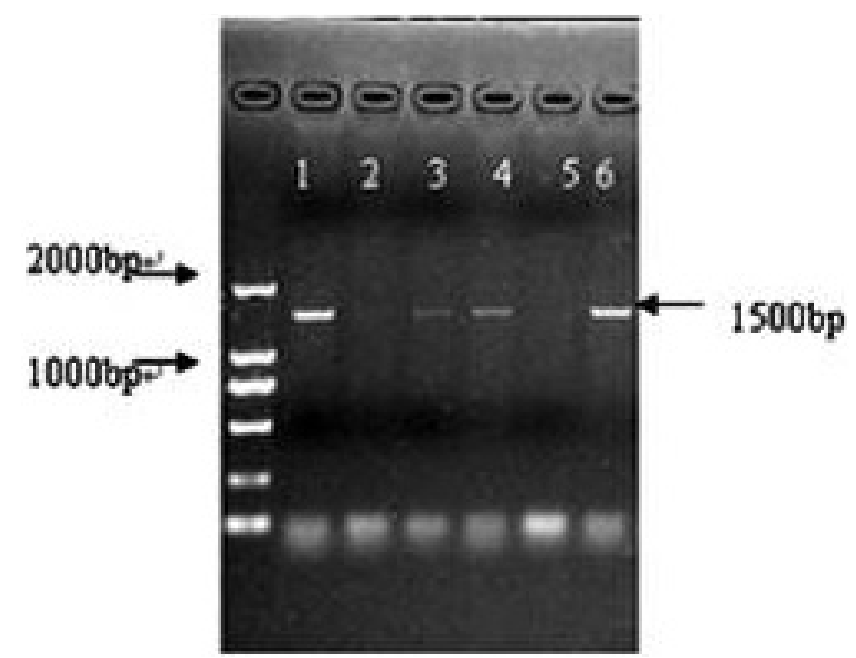

Figure 5-2. PCR detection of ICE1 transgene in tomato plants. Lanes 1-5, transgenic tomato; Lane 6, p3301-ICE1; $\mathrm{M}$, DNA marker Trans2k. 


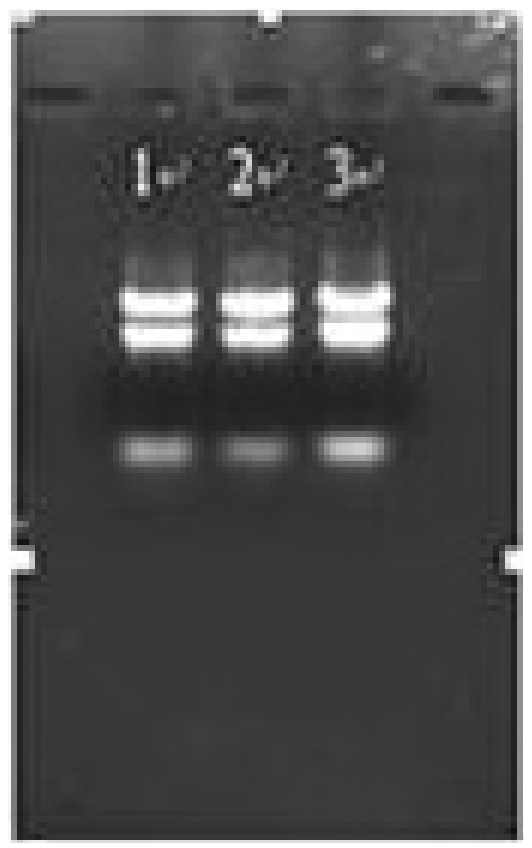

Figure 5-3. Electrophoresis of tomato RNA. Lanes 1-3, transgenic tomato.

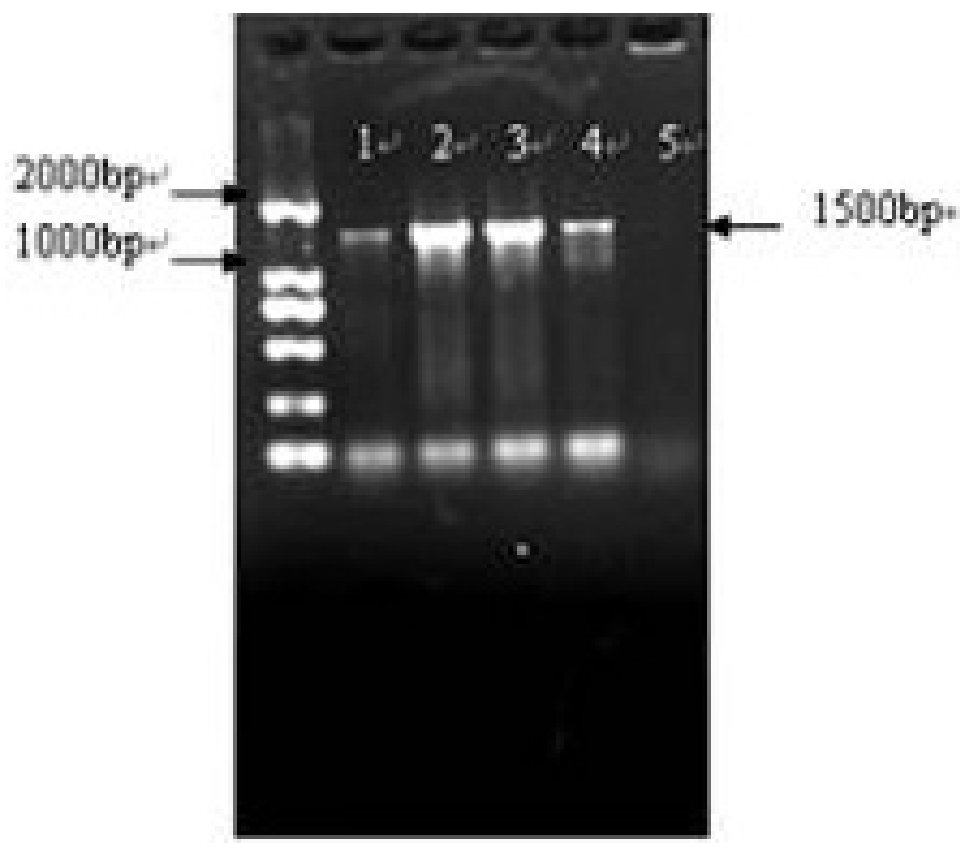

Figure 5-4. RT-PCR detection of ICE1 transgene in tomato plants. Lanes 1-3, transgenic tomato; Lane 4, positive control; Lane 5, negative control; M, DNA marker Trans2k. 


\section{Cold resistance of transgenic plants}

The MDA content in the transgenic plants showed a declining trend with increasing exposure to low-temperature from $0 \mathrm{~h}$ to $72 \mathrm{~h}$, although the increase was slight from $0 \mathrm{~h}$ to 24 $\mathrm{h}$. This was also true for the control plants. At $72 \mathrm{~h}$, the content of MDA in transgenic plants was significantly lower than that of the control plants (Figure 6-1). The Pro contents of transgenic plants and control plants increased under low-temperature stress. Compared with control plants, the Pro content in the transgenic plants increased with increasing stress duration (Figure 6-2). The changes in CAT and POD activity followed similar trends in the transgenic and control plants, increasing first and then decreasing over the low-temperature stress period. Under low-temperature stress, the CAT and POD activity levels in the transgenic plants increased significantly compared with those in the control plants. The CAT and POD activity levels were at their highest at $24 \mathrm{~h}$ (Figure 6-3, 6-4).

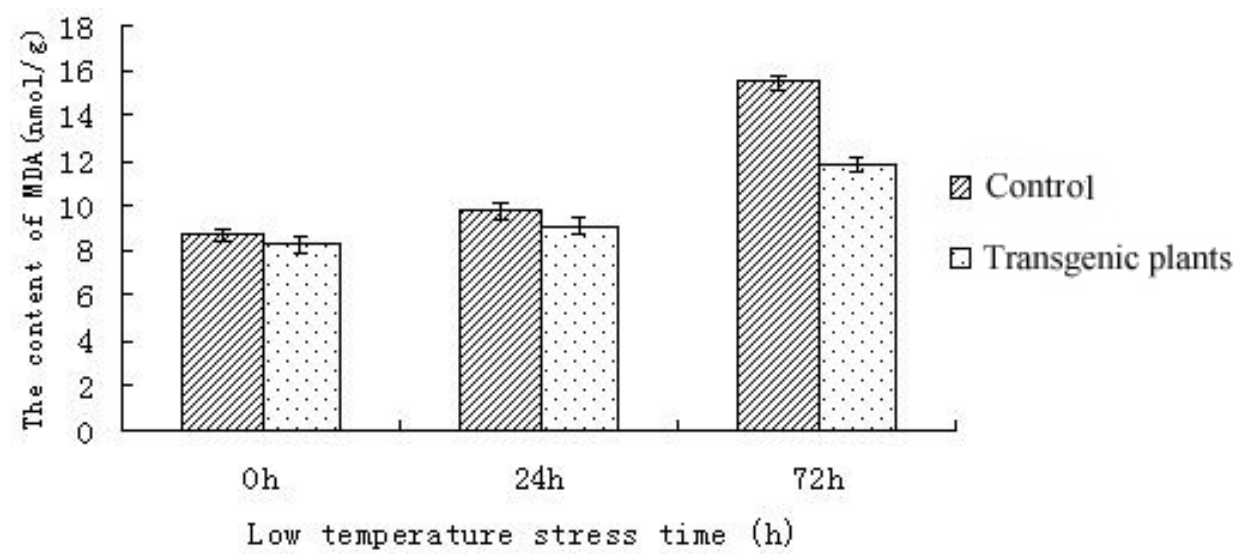

Figure 6-1. Malondialdehyde (MDA) content in transgenic ICE1 tomato plants under cold stress conditions.

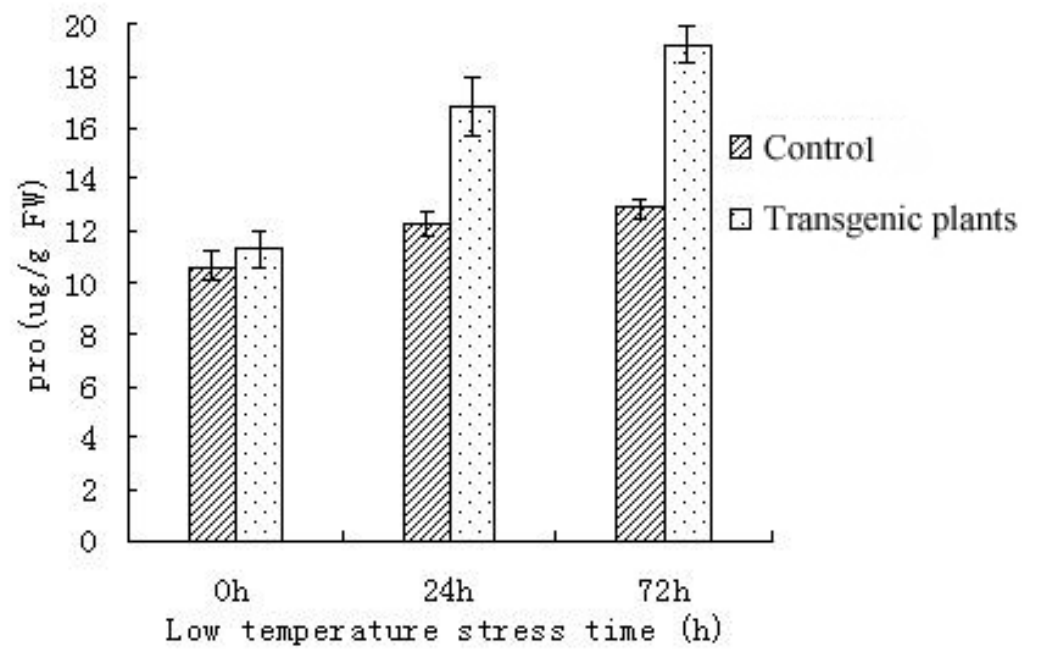

Figure 6-2. Proline (Pro) content in transgenic ICE1 tomato plants under cold stress conditions. 


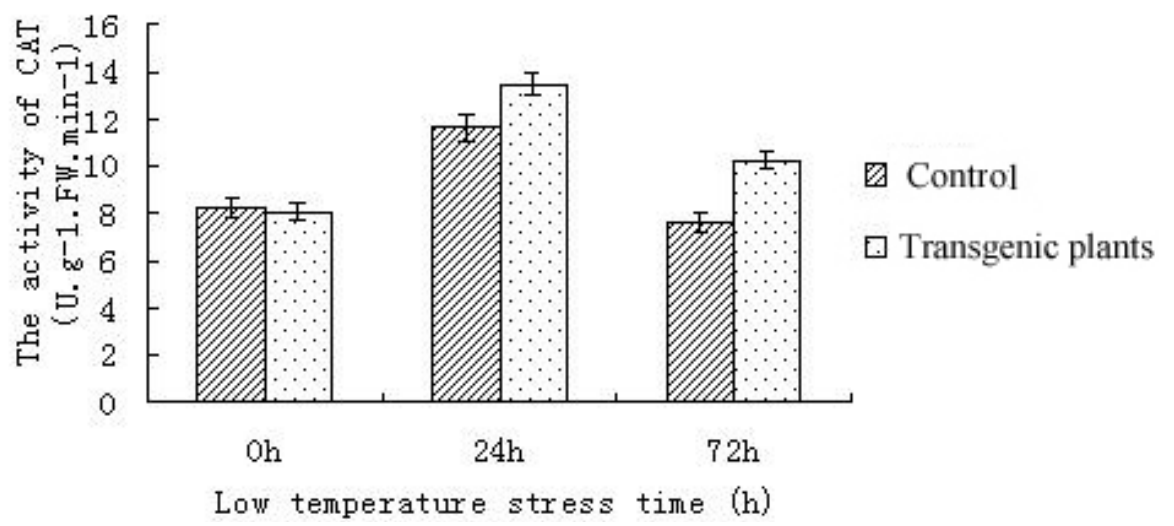

Figure 6-3. Effect of low temperature on catalase (CAT) activity in transgenic ICE1 tomato plants.

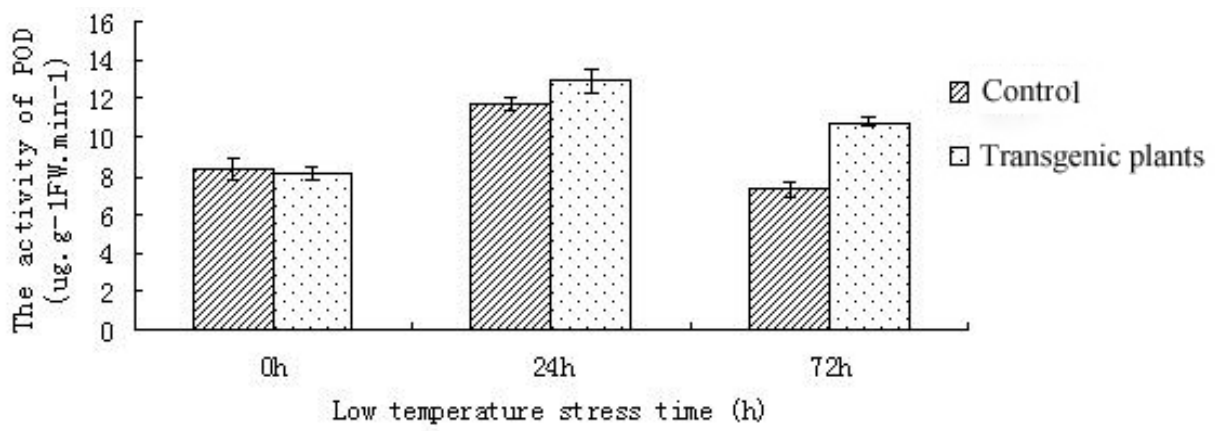

Figure 6-4. Effect of low temperature on peroxidase (POD) activity in transgenic ICE1 tomato plants.

\section{DISCUSSION}

Chinnusamy et al. (2003) found that the constitutive expression of ICE1 increases the transcriptional expression of $C B F 3$ under low temperatures and improves the ability of transgenic plants to resist the cold (Agarwal et al., 2006; Miura et al., 2007). Lee et al. (2005) found that overexpression of the ICE1 gene does not affect normal growth of $A$. thaliana and significantly improves the frost resistance in transgenic $A$. thaliana seedlings. Many low-temperature response genes are controlled by ICE1, not only under low temperatures, but also at normal temperatures.

Ma (2007) genetically modified corn successfully using the expression vector pCAMBIA3301. In the present research, ICE1 was inserted into the binary vector successfully, using a two-step digestion with $\mathrm{Ncol}$ at $37^{\circ} \mathrm{C}$ and BstEll at $60^{\circ} \mathrm{C}$. During the selection process for transgenic calli, we found that Kan at $10 \mathrm{mg} \cdot \mathrm{L}^{-1}$ significantly inhibited the induction of the cotyledon's calli and the regeneration of adventitious buds. At higher Kan concentrations, the frequency of transgenic events decreased significantly, and growth vigor of the plant was diminished. When the Kan concentration was increased to $20 \mathrm{mg} \cdot \mathrm{L}^{-1}$, the adventitious buds remained undifferentiated for untransformed calli. Therefore, Kan at $20 \mathrm{mg} \cdot \mathrm{L}^{-1}$ was chosen for transgenic callus selection.

In our experiments, transgenic ICE1 tomato plants were subjected to low-temperature stress. The expression of the ICE1 transgene resulted in reduced MDA content, increased 
Pro content, and increased CAT and POD activities. The MDA level could be interpreted as a peroxidation indicator of membrane lipid, which may, to a certain extent, reflect the quantity of damaged cells. Pro is an important and effective osmotic adjuster in plant cells, and is shown to accumulate in biotically- and abiotically-stressed plants. CAT and POD are key enzymes that scavenge active oxygen radicals in plants, to reduce injury to the plant (Ma et al., 1998). We also found that MDA and Pro contents, and the CAT and POD activity levels, in the transgenic tomato were roughly the same as those in control plants before the cold stress. These data suggest that ICE1 has no influence on the physiology and biochemistry of plants grown at a normal temperature. These results are consistent with those of Chinnusamy et al. (2003). With prolonged exposure to low-temperature, Pro content and CAT and POD activity levels in the transgenic ICE1 plants were significantly higher than those in the control plants. This is probably due to the induction of the ICE1 transgene overexpression by low temperatures for cold resistance. However, whether ICE1 can effectively protect the tomato against low-temperature stresses and whether the low-temperature tolerance can be stably inherited remain to be investigated.

In conclusion, the present study shows that ICE1 could effectively decrease cold-sensitivity in the tomato plant. This suggests that ICE1, as a promising transcriptional factor, could be targeted to improve cold-resistance in crops through genetic engineering. However, field trials are needed to determine the effectiveness of the transgenic ICE1 plants for their cold resistance.

\section{Conflicts of interest}

The authors declare no conflict of interest.

\section{ACKNOWLEDGMENTS}

The project was supported by funds from the Heilongjiang Provincial Department of Education (grant \#11531019), the Special Fund Project for Harbin Technological Innovation Talent (grant \#2007RFLXN004), the Projects for Innovative Research Teams at Northeast Agricultural University (grant \#CXT002-2-3), Heilongjiang Provincial Department of Education's Key Laboratory of Biology for Vegetables in Cold Regions, and Collaborative Innovation Center for Development and Utilization of Forest Resources, Harbin, China.

\section{REFERENCES}

Agarwal M, Hao YJ, Kapoor A, Dong CH, et al. (2006). AR2R3 type MYB transcription factor is involved in the cold regulation of CBF genes and in acquired freezing tolerance. Biol. Chem. 281: 37636-37645.

Cakmak I and Marschner H (1992). Magnesium deficiency and high light intensity enhance activities of superoxide dismutase, ascorbate peroxidase, and glutathione reductase in bean leaves. Plant Physiol. 98: 1222-1227.

Chinnusamy V, Ohta M, Kanrar S, Lee BH, et al. (2003). ICE1: a regulator of cold-induced transcriptome and freezing tolerance in Arabiopsis. Genes Dev. 17: 1043-1054.

Chen L, Chen Y and Chen FD (2012). The constitutive expression of Chrysanthemum dichrum ICE1 in Chrysanthemum grandiflorum improves the level of low temperature, salinity and drought tolerance. Plant Cell Rep. 31: $1747-1758$.

Huang JQ (2005). Cold resistance gene cloning and Agrobacterium tumefaciens- mediated the ICE1 gene transformation citrus research. Master's thesis, Huazhong Agricultural University, Wuhan.

Hsieh TH, Lee JT, Yang PT, Chiu LH, et al. (2002). Heterology expression of the Arabidopsis C-repeat/dehydration response element binding factor 1 gene confers elevated tolerance to chilling and oxidative stresses in transgenic tomato. Plant Physiol. 129: 1086-1094.

Lee B, Henderson DA and Zhu JK (2005). The Arabidopsis cold-responsive transcriptome and its regulation by ICE1. Plant Cell 17: 3155-3175. 
Li D, Jiang XM and Yu XH (2010). CBF gene cloning and expression analysis. Plant Physiol. Commun. 46: 245-248.

Lin D, Wei YT and Wang SG (2000). Tomato resistance to low temperature research progress. Shenyang Agricult. Univ. 31 : 585-589.

Lin YZ, Guo H and Liu CX (2011). Molecular cloning and expression analysis of cold-resistant transcription factor ICE1 from Eucalyptus camaldulensis L. Plant Physiol. J. 47: 488-494.

Liu LY, Duan LS, Zhang JC and Zhang ZX (2010). Cucumber (Cucumis sativus L.) over-expressing cold-induced transcriptome regulator ICE1 exhibits changed morphological characters and enhances chilling tolerance. Sci. Hortic. 124: 29-33.

Liu Q, Kasuga M, Sakuma Y, Abe H, et al. (1998). Two transcription factors, DREB1 and DREB2, with an EREBP/AP2 DNA binding domain separate two cellular signal transduction pathways in drought- and low-temperature-responsive gene expression, respectively, in Arabidopsis. Plant Cell 10: 1391-1406.

Lin YZ, Zhang ZY and Liu CX (2007). In silico Cloning and Analyzing of Ps/CE1 from Populus suaveolens, A Freezing-resistant Transcription Factor. Food Agric. Organization Unit. Nat. 5: 424-430.

Ma DH, Lu YH and Pang JA (1998). Low temperature of cucumber seedling membrane lipid peroxidation influence. J. Hortic. 25: $62-65$.

Ma L (2007). Maize dwarf mosaic virus gene genetic transformation studies. Doctoral thesis, Shandong Agricultural University, Taian.

Miura K, Jin JB, Lee JY, Yoo CY, et al. (2007). SIZ1-mediated sumoylation of ICE1 controls CBF3/DREB1A expression and freezing tolerance in Arabidopsis. Plant Cell 19: 1403-1414.

Savitch LV, Allard G, Seki M, Robert LS, et al. (2005). The effect of overexpression of two Brassica CBF/DREB1-like transcription factors on photosynthetic capacity and freezing tolerance in Brassica napus. Plant Cell Physiol. 46: 1525-1539.

Stockinger EJ, Gilmour SJ and Thomashow MF (1997). Arabidopsis thaliana CBF1 encodes an AP2 domain-containing transcription activator that binds to the C-repeat/DRE, a cis-acting DNA regulatory element that stimulates transcription in response to low temperature and water deficit. Proc. Natl. Acad. Sci. U.S.A. 94: 1035- 1040.

Thomashow MF (1999). Plant cold acclimation: freezing tolerance genes and regulatory mechanisms. Annu. Rev. Plant Physiol. Plant Mol. Biol. 50: 571-599.

Xiang DJ, Man LL and Yin KD (2008). Arabidopsis thaliana ICE1 gene transformation of rice for the further study. Biol. Technical Bull. 6: 87-90, 96

Zhang XZ, Tan GR, Huang YJ and Song YH (1989). Plant physiology experiment technology. Liaoning Science and Technology Press, Shenyang.

Zhang Y, Xiang DJ and Yin KD (2008). Transformation of ICE1 gene into cymbidium grandiftorium mediated by agrobacterium. China Agricult. Bull. 24: 40-43.

Zhao LL (2007). Apple Md SAMDC2 and Md ICE1 gene function identification and stress resistance research. Master's thesis, Shandong Agricultural University, Taian.

Zhao SJ, Liu HS and Dong XC (1998). Plant physiology experiments guidance. China Agricultural Science and Technology Press, Beijing, 149-161.

Zheng YY, Cui BM, Chang MJ and Peng M (2009). Expression of At/CE1 gene in transgenic tobacco plants show increased tolerance to freezing stress.. Northwest Acta Bot. Sin. 29: 75-79.

Zou Q (1998). Plant physiology and biochemistry experiments guidance. China Agriculture Press, Beijing. 